\title{
VARIABILITY IN STRESS TOLERANCE AND POTENTIAL OF ENDOPHYTIC BACTERIA TO IMPROVE CHICKPEA GROWTH UNDER WATER LIMITED CONDITIONS
}

\author{
Muhammad Usman Jamshaid ${ }^{1,2, *}$, Zahir Ahmad Zahir ${ }^{1}$, Hafiz Naeem Asghar ${ }^{1}$ and Amer Jamil ${ }^{3}$ \\ ${ }^{1}$ Institute of Soil and Environmental Sciences, University of Agriculture, Faisalabad, Pakistan; ${ }^{2}$ Department of Soil \\ and Environmental Sciences, Muhammad Nawaz Shareef University of Agriculture, Multan, Pakistan; ${ }^{3}$ Department \\ of Biochemistry, University of Agriculture, Faisalabad, Pakistan. \\ "Corresponding author's e-mail: usmanjamshaid@gmail.com
}

Plant growth promoting bacteria have been employed as a biotechnological tool for ameliorating the impacts of water deficit stress on plants. However, endophytic bacteria colonizing within plant tissues could be of great benefit to the crops. In the present study, forty strains of endophytic bacteria were isolated and tested for their survivability under water deficit conditions. Twelve bacterial isolates showing the highest potential to survive under water deficit conditions were evaluated for inducing stress tolerance in chickpea seedlings at different levels of water deficit stress (i.e. - $0.04,-0.70$ and $-1.24 \mathrm{MPa}$ ) under gnotobiotic conditions. Bacterial inoculation with isolates Cs8, Cs10 and Cp7 prominently increased the root length of chickpea over un-inoculated control. Significantly higher root/shoot dry biomass was observed in response to inoculation with bacterial isolates $\mathrm{Cs} 8, \mathrm{Cs} 10, \mathrm{Cp} 3$ and $\mathrm{Cp} 7$ as compared to un-inoculated control. Moreover, all the endophytic bacterial isolates were capable to produce auxins, catalase, oxidase and exopolysaccharides. It is concluded that the endophytic bacteria colonizing internal tissues of pods and shoot of chickpea have better potential to improved growth and biomass of chickpea seedling under reduced water conditions.

Keywords: Endophytic bacteria, drought, chickpea, PEG 6000.

Abbreviations: PGPR, Plant Growth Promoting Rhizobacteria; DMSTI, Dry Matter Stress Tolerance Index; LB, Lauriabertani; TSB, Tryptic soy broth; PEG, Polyethylene glycol

\section{INTRODUCTION}

The production of agricultural crops is reducing due to the prevalence of drought like situations in the world (Fahad et al., 2017). Inoculation with plant growth promoting bacteria has been devised as a beneficial strategy for improving the fitness of crop plants especially under harsh environmental conditions. Bacteria in the rhizosphere face various conditions to ensure their survival through competition with indigenous microflora for nutrition and harsh environmental conditions before playing their role as plant growth promoter (Martinez et al., 2010). Predation by protozoans aggravates the problem of inoculums failure in field conditions by limiting survival of plant growth promoting bacteria (PGPB) in the rhizosphere. Ultimately, the role of rhizosphere bacteria as plant growth promoter is verily dependent on their capability to survive and flourish under hostile environments (Rivera et al., 2008).

While in distressed conditions some bacteria become advantageous due to their capability to enter, survive and express their plant beneficial traits inside the plant tissues. They live for the entire or part of their life cycle inside the plant without being pathogenic and are termed as endophytes (Hardoim et al., 2008). Bacteria as endophytes escape/avoid the competition with indigenous microflora for space and resources and adverse soil conditions. They get incubation in plant tissue at optimal temperature, space and nutrition (Beattie, 2007; Rosenblueth and Martinez-Romero, 2006). Endophytic bacteria are almost similar in their plant growth promoting attributes to rhizobacteria. They increase plant vigor and induce tolerance/resistance against biotic/abiotic stresses like drought (Hallmann et al., 1997; Naveed et al., 2014) and modulate the plant stress response (Dudeja and Giri, 2014). The plant growth promoting mechanisms by endophytic bacteria include the production of phytohormones, nitrogen fixation, siderophores production and production of antimicrobial compounds against plant pathogens (Hallmann et al.,1997; Rosenblueth and MartinezRomero, 2006; Mitter et al., 2013). It has been observed that endophytic bacteria improve plant growth, biomass, root growth and protect the plants from drought by supplying growth regulators, osmolytes and nutrients (Kavamura et al., 2013; Egamberdieva, 2017).

Using endophytes on behalf of their advantages to avoid harsh soil environments is a new trend in sustainable agriculture. Though, researchers have tried different endophytes to improve growth, physiology, yield and abiotic stress tolerance in cereals. However, endophytes in legumes other than 
rhizobium have not been studied yet. Therefore, in present investigation, we have isolated and identified the potential plant growth promoting endophytic bacteria from the roots, stems, leaves and pods tissues of chickpea for ameliorating impacts of water deficit on chickpea.

\section{MATERIALS AND METHODS}

Isolation and preservation of endophytic bacteria: Healthy and disease free plant tissues (roots, stems, leaves, pods) of chickpea (grown in arid to semi-arid regions of PunjabPakistan) were sampled, washed, blotted and stored in refrigerator before the initiation of isolation procedure. Isolation of the endophytic bacteria was carried out in Soil Microbiology and Biochemistry Lab, Institute of Soil and Environmental Sciences, University of Agriculture Faisalabad. The plant tissues were surface sterilized by dipping in alcohol (70\%) for $1 \mathrm{~min}$ followed by 3-5 min dip in sodium hypochlorite $(3.5 \%)$ and 4 times washing with sterilized distilled water (Long et al., 2008). Sterilized plant tissues were crushed in sterilized saline $(0.85 \%)$ water. Dilution plate technique was followed to isolate the endophytic bacteria by using tryptic soy agar (TSA) as a growth medium (Evers et al., 2015). The plates were incubated at $28 \pm 1^{\circ} \mathrm{C}$ for $48 \mathrm{~h}$ to observe bacterial growth. Prolific bacterial colonies from each tissue were separated and purified by repeated streaking and preserved in glycerol $(40 \%)$ at $-40^{\circ} \mathrm{C}$ for future use. Ten isolates from each tissue were selected for further experimentation and coded accordingly (Table 1).

Table 1. Coding of endophytic bacteria isolated from roots, stems, leaves and pods tissues of chickpea.

\begin{tabular}{cccc}
\hline Roots & Stems & Leaves & Pods \\
\hline${ }^{1} \mathrm{Cr} 1$ & ${ }^{2} \mathrm{Cs} 1$ & ${ }^{3} \mathrm{C} 11$ & ${ }^{4} \mathrm{Cp} 1$ \\
$\mathrm{Cr} 2$ & $\mathrm{Cs} 2$ & $\mathrm{Cl} 2$ & $\mathrm{Cp} 2$ \\
$\mathrm{Cr} 3$ & $\mathrm{Cs} 3$ & $\mathrm{Cl} 3$ & $\mathrm{Cp} 3$ \\
$\mathrm{Cr} 4$ & $\mathrm{Cs} 4$ & $\mathrm{Cl} 4$ & $\mathrm{Cp} 4$ \\
$\mathrm{Cr} 5$ & $\mathrm{Cs} 5$ & $\mathrm{Cl} 5$ & $\mathrm{Cp} 5$ \\
$\mathrm{Cr} 6$ & $\mathrm{Cs} 6$ & $\mathrm{Cl} 6$ & $\mathrm{Cp} 6$ \\
$\mathrm{Cr} 7$ & $\mathrm{Cs} 7$ & $\mathrm{Cl}$ & $\mathrm{Cp} 7$ \\
$\mathrm{Cr} 8$ & $\mathrm{Cs} 8$ & $\mathrm{Cl} 8$ & $\mathrm{Cp} 8$ \\
$\mathrm{Cr} 9$ & $\mathrm{Cs} 9$ & $\mathrm{Cl} 19$ & $\mathrm{Cp} 9$ \\
$\mathrm{Cr} 10$ & $\mathrm{Cs} 10$ & $\mathrm{Cl} 10$ & $\mathrm{Cp} 10$ \\
\hline
\end{tabular}

${ }^{1}$ Chickpea roots $(\mathrm{Cr}),{ }^{2} \mathrm{Chickpea}$ stems $(\mathrm{Cs}),{ }^{3} \mathrm{Chickpea}$ leaves (Cl), ${ }^{4}$ Chickpea pods $(\mathrm{Cp})$

Water deficit stress abiding ability of endophytic bacteria: Bacterial isolates from respective tissues were subjected to various levels of osmotic stress employed by using polyethylene glycol (PEG-6000) such as -0.05, -0.65, -1.57, 2.17 and $-2.23 \mathrm{MPa}$. Osmotic stress treatments were established in sterilized $15 \mathrm{~mL}$ test tubes containing $7 \mathrm{~mL}$ Lauria-bertani (LB) broth by the addition of Polyethylene glycol 6000 (PEG-6000) (Busse and Bottomley, 1989) Osmotic potential of broth media was measured by osmometer (OSMOMAT-030-D, Gonotec, Germany) at respective PEG-6000 levels. Freshly prepared culture of each isolate $\left(0.5 \mathrm{OD} \approx 10^{7}\right.$ cells $\left.\mathrm{mL}^{-1}\right)$ was inoculated into the sterilized conical flask and incubated for two days in orbital shaking incubator at $28 \pm 1^{\circ} \mathrm{C}$ and $100 \mathrm{rpm}$. Three sets of each treatment and a control without bacteria were maintained. Bacterial growth was determined by measuring optical density at $\lambda 600 \mathrm{~nm}$ using spectrophotometer (Nicolet Evolution 300, Thermo Electron Corporation) (Asghar et al., 2015) and bacterial cell counts were determined by dilution plate technique. Bacteria showing higher OD and cell count under water deficit stress were considered as water deficit stress tolerant.

Plant growth promoting potential of endophytic bacteria: Water deficit stress tolerant endophytic bacterial isolates, three from each part i.e. root $(\mathrm{Cr} 1, \mathrm{Cr} 4, \mathrm{Cr} 10)$, stem (Cs6, Cs8, $\mathrm{Cs} 10)$, leaf $(\mathrm{Cl} 3, \mathrm{Cl}, \mathrm{Cl} 7)$ and pod $(\mathrm{Cp} 3, \mathrm{Cp} 7, \mathrm{Cp} 10)$ were selected for plant growth promoting experiment in pouches using chickpea (Cicer arietinum L.) cv. Punjab 2008 as test crop under controlled conditions in growth room of Soil Microbiology and Biochemistry Lab, Institute of Soil and Environmental Sciences, University of Agriculture Faisalabad. Freshly prepared inocula of each bacterial isolate in $\mathrm{LB}$ broth $\left(0.5 \mathrm{OD}=10^{7}\right.$ cells $\left.\mathrm{mL}^{-1}\right)$ were used for seed inoculations. Surface sterilized pre-germinated seeds were dipped in inoculum for $20 \mathrm{~min}$ for inoculation. Control was maintained by dipping seeds in sterilized inoculum. Pouches were arranged on the shelf of growth room in completely randomized design with three replications. Day length was adjusted as $14 \mathrm{~h}$ dark and $10 \mathrm{~h}$ light and suitable temperature $22-25^{\circ} \mathrm{C}$ was maintained. The plants were irrigated with $1 / 2$ strength Hoagland's solution. After three days of sowing, the water deficit stress treatments were applied by using PEG6000 in $1 / 2$ strength Hoagland's solution to maintain water potentials of $-0.04,-0.70$ and $-1.24 \mathrm{MPa}$ (Michel, 1983). Plants were harvested after 20 days and root/shoot fresh/dry biomass and length parameters were recorded.

Dry matter stress tolerance index (DMSTI): Dry matter stress tolerance index was calculated by dividing the dry weight of inoculated seedlings under stress (DWI or St) with the dry weight of un-inoculated and unstressed seedlings (DWUI and USt) (Ashraf et al., 2006).

$$
\text { DMSTI }=\frac{(\text { DWI and St })}{(\text { DWUI and USt })} \times 100
$$

Where DWI is the dry weight of inoculated seeding; DWUI is the dry weight of un-inoculated seedling; $\mathrm{St}=$ stressed seedling; USt = un-stressed seedling.

Bacterial characterization: Auxin production in the presence and absence of L-tryptophan was determined spectrophotometrically (Nicolet Evolution 300, Thermo Electron Corporation) following the procedure described by Sarwar et al. (1992). Exopolysaccharides production was 
assessed using RCV-glucose media as described by Ashraf et al. (2004). Catalase and oxidase activities were observed using the procedures by MacFaddin (1980) and Steel (1961), respectively. Microbial aggregation ability was determined using modified procedure of Madi and Henis (1989) and calculated using the formula

$$
\% \text { Aggregation }=\frac{\mathrm{OD} 2-\mathrm{OD} 1}{\mathrm{OD} 2} \times 100
$$

Where, OD1 (absorbance of aliquot after $20 \mathrm{~min}$ settling of fresh inocula) and OD2 (after 1 min vortex of the inocula) were measured at $540 \mathrm{~nm}$ on spectrophotometer.

Statistical analysis: Data were analyzed by two-way analysis of variance (ANOVA) (Steel et al., 1997) and means were compared using LSD test. Software used for the analysis was Statistix 8.1 (Analytical Software, USA).

\section{RESULTS}

Water deficit stress tolerance capability of endophytic bacteria: Following the OD and cell count of bacterial strains isolated from chickpea roots (Table 2) at various water potentials (-0.65 $\mathrm{MPa},-1.57 \mathrm{MPa},-2.17 \mathrm{MPa},-2.23 \mathrm{MPa})$. A significant decrease in cell count and OD was recorded with gradual decrease in water potentials. However, bacterial isolates $\mathrm{Cr} 3, \mathrm{Cr} 5$ and $\mathrm{Cr} 10$ remained prominent among all bacterial isolates with higher $\mathrm{OD}$ values at $-0.65 \mathrm{MPa}$. Whereas at $-1.57 \mathrm{MPa}$, the OD values of $\mathrm{Cr} 3, \mathrm{Cr} 7$ and $\mathrm{Cr} 10$ were higher as compared to other bacterial isolates. At -2.17 and $-2.23 \mathrm{MPa}$, the OD values trend was quite different from each other showing prominent group of three isolates as $(\mathrm{Cr} 4$, $\mathrm{Cr} 7, \mathrm{Cr} 10)$ and $(\mathrm{Cr} 1, \mathrm{Cr} 3, \mathrm{Cr} 5)$, respectively. As for as, bacterial cell counts at various water potential levels were concerned, bacterial isolate $\mathrm{Cr} 3$ was most prominent with significantly high cell counts at $-0.65,-1.57,-2.17$ and -2.23 MPa water potentials followed by $\mathrm{Cr} 2$ with prominence at $1.57,-2.17$ and $-2.23 \mathrm{MPa}$. In addition to $\mathrm{Cr} 2$ and $\mathrm{Cr} 3$, other isolates also showed significantly high cell counts at -0.65 $\mathrm{MPa}$ (Cr8, Cr9), -1.57 MPa (Cr5), -2.17 MPa (Cr10) and $2.23 \mathrm{MPa}(\mathrm{Cr} 7)$. From overall observation for OD values and cell counts, bacterial isolates $\mathrm{Cr} 2, \mathrm{Cr} 3$ and $\mathrm{Cr} 10$ were

Table 2. Drought tolerance assay of endophytic bacteria isolated from chickpea roots at different PEG induced osmotic stress levels.

\begin{tabular}{|c|c|c|c|c|c|c|c|c|c|c|c|c|}
\hline \multirow[t]{2}{*}{ Isolates } & \multicolumn{6}{|c|}{ Optical Density (OD) $(n=3)$} & \multicolumn{6}{|c|}{ Cell Count $\left(\right.$ CFU mL $\left.\mathrm{mL}^{-1} \times 10^{-3}\right)(\mathrm{n}=3)$} \\
\hline & $\begin{array}{c}-0.05 \\
\text { (MPa) }\end{array}$ & $\begin{array}{c}-0.65 \\
(\mathrm{MPa}) \\
\end{array}$ & $\begin{array}{c}-1.57 \\
\text { (MPa) }\end{array}$ & $\begin{array}{c}-2.17 \\
(\mathrm{MPa})\end{array}$ & $\begin{array}{c}-2.23 \\
(\mathrm{MPa})\end{array}$ & Mean & $\begin{array}{c}-0.05 \\
\text { (MPa) }\end{array}$ & $\begin{array}{c}-\mathbf{- 0 . 6 5} \\
\text { (MPa) }\end{array}$ & $\begin{array}{c}-1.57 \\
(\mathrm{MPa})\end{array}$ & $\begin{array}{c}-2.17 \\
\text { (MPa) }\end{array}$ & $\begin{array}{c}-2.23 \\
\text { (MPa) }\end{array}$ & Mean \\
\hline $\mathrm{Cr} 1$ & $4.8 \mathrm{ijk}$ & $4.7 \mathrm{jk}$ & $4.21 \mathrm{mn}$ & $4.0 n-q$ & $3.8 \mathrm{pqr}$ & $4.3 \mathrm{EF}$ & $38.8 b-f$ & $35.8 \mathrm{fg}$ & $20.8 \mathrm{mno}$ & $20.4 m-p$ & 11.6stu & $25.5 \mathrm{~F}$ \\
\hline $\mathrm{Cr} 2$ & $5.8 \mathrm{f}$ & $5.2 \mathrm{gh}$ & $4.9 \mathrm{ij}$ & $3.1 \mathrm{~s}$ & $2.7 \mathrm{t}$ & $4.3 \mathrm{E}$ & 41.1abc & $40.1 \mathrm{a}-\mathrm{d}$ & $26.2 \mathrm{hij}$ & 25.3hi & $15.9 \mathrm{qr}$ & 29.7B \\
\hline $\mathrm{Cr} 3$ & $7.1 \mathrm{a}$ & $6.9 \mathrm{a}$ & $6.2 \mathrm{~d}$ & $4.21 \mathrm{mn}$ & $3.7 \mathrm{r}$ & $5.6 \mathrm{~A}$ & $41.9 \mathrm{ab}$ & $41.2 \mathrm{abc}$ & $34.2 \mathrm{~g}$ & 29.0ijk & $18.1 \mathrm{opq}$ & $32.9 \mathrm{~A}$ \\
\hline $\mathrm{Cr} 4$ & $4.6 \mathrm{k}$ & $4.7 \mathrm{jk}$ & $4.8 \mathrm{jk}$ & $4.9 \mathrm{ij}$ & 4.8ijk & $4.8 \mathrm{D}$ & $42.6 a$ & 41.1abc & 23.6i-m & $21.8 \mathrm{~h}$ & 14.6rst & $28.7 \mathrm{BC}$ \\
\hline $\mathrm{Cr} 5$ & $6.3 \mathrm{~cd}$ & 6.0de & 5.1hi & $4.0 \mathrm{~m}-\mathrm{p}$ & $3.90-r$ & $5.1 \mathrm{C}$ & $38.5 \mathrm{c}-\mathrm{f}$ & 37.1d-g & 26.1hij & $21.81 \mathrm{mn}$ & $11.4 \mathrm{tu}$ & 27.0DE \\
\hline Cr6 & $5.7 f$ & $5.4 \mathrm{~g}$ & 3.8pqr & $2.7 \mathrm{t}$ & $1.8 \mathrm{v}$ & $3.9 \mathrm{G}$ & 36.6efg & $36.2 \mathrm{fg}$ & 20.9mno & $22.41 \mathrm{mn}$ & $14.8 \mathrm{rs}$ & $26.2 \mathrm{EF}$ \\
\hline $\mathrm{Cr} 7$ & $6.6 b$ & $5.8 \mathrm{f}$ & $5.4 \mathrm{~g}$ & $4.7 \mathrm{jk}$ & $3.0 \mathrm{~s}$ & $5.1 \mathrm{C}$ & $40.4 a-d$ & $38.4 c-f$ & $23.1 \mathrm{j}-\mathrm{m}$ & $24.4 \mathrm{klm}$ & $17.4 \mathrm{u}$ & 28.7BC \\
\hline $\mathrm{Cr} 8$ & $5.2 \mathrm{gh}$ & 4.8ijk & $4.1 \mathrm{mno}$ & $2.4 \mathrm{u}$ & $1.9 \mathrm{v}$ & $3.7 \mathrm{H}$ & $42.5 \mathrm{a}$ & $41.5 \mathrm{abc}$ & $24.2 \mathrm{i}-1$ & $20.8 \mathrm{i}-1$ & 11.9pqr & $28.2 \mathrm{CD}$ \\
\hline $\mathrm{Cr} 9$ & 5.1hi & $4.9 \mathrm{ij}$ & 4.41 & $3.8 \mathrm{qr}$ & $3.0 \mathrm{~s}$ & $4.2 \mathrm{~F}$ & 41.2abc & $42.3 \mathrm{a}$ & $21.71 \mathrm{mn}$ & $19.1 \mathrm{mno}$ & $9.1 \mathrm{stu}$ & 26.7EF \\
\hline Cr10 & $7.0 \mathrm{a}$ & $6.5 b c$ & $5.9 \mathrm{ef}$ & $4.31 \mathrm{~m}$ & $2.5 \mathrm{tu}$ & $5.2 \mathrm{~B}$ & $42.0 \mathrm{ab}$ & 39.8a-e & 22.3k-n & $26.8 n-q$ & $10.3 \mathrm{u}$ & 28.2CD \\
\hline Mean & $5.8 \mathrm{~A}$ & $5.5 \mathrm{~B}$ & $4.9 \mathrm{C}$ & $3.8 \mathrm{D}$ & $3.1 \mathrm{E}$ & & $40.6 \mathrm{~A}$ & 39.4B & $24.3 \mathrm{C}$ & $23.2 \mathrm{D}$ & $13.5 \mathrm{E}$ & \\
\hline LSD & \multicolumn{6}{|c|}{ Drought $(0.08)$, Isolate $(0.11)$, Drought* Isolate $(0.25)$} & \multicolumn{6}{|c|}{ Drought (1.04), Isolate (1.57), Drought* Isolate (3.28) } \\
\hline
\end{tabular}

Table 3. Drought tolerance assay of endophytic bacteria isolated from chickpea stem at different PEG induced osmotic stress levels.

\begin{tabular}{|c|c|c|c|c|c|c|c|c|c|c|c|c|}
\hline \multirow[t]{2}{*}{ Isolates } & \multicolumn{6}{|c|}{ Optical Density (OD) $(n=3)$} & \multicolumn{6}{|c|}{ Cell Count $\left(\mathrm{CFU} \mathrm{mL} \mathrm{mL}^{-1} \times \mathbf{1 0}^{-3}\right)(\mathrm{n}=3)$} \\
\hline & $\begin{array}{c}-\mathbf{0 . 0 5} \\
(\mathrm{MPa})\end{array}$ & $\begin{array}{c}-0.65 \\
\text { (MPa) }\end{array}$ & $\begin{array}{c}-1.57 \\
\text { (MPa) }\end{array}$ & $\begin{array}{c}-2.17 \\
\text { (MPa) }\end{array}$ & $\begin{array}{c}-2.23 \\
\text { (MPa) }\end{array}$ & Mean & $\begin{array}{c}-\mathbf{0 . 0 5} \\
\text { (MPa) }\end{array}$ & $\begin{array}{c}-0.65 \\
\text { (MPa) }\end{array}$ & $\begin{array}{c}-1.57 \\
\text { (MPa) }\end{array}$ & $\begin{array}{c}-2.17 \\
\text { (MPa) }\end{array}$ & $\begin{array}{c}-2.23 \\
(\mathrm{MPa})\end{array}$ & Mean \\
\hline Cs1 & 4.11 & $3.9 \mathrm{~m}$ & $2.5 \mathrm{t}$ & $1.5 \mathrm{w}$ & $1.4 \mathrm{w}$ & $2.7 \mathrm{I}$ & $28.8 \mathrm{cde}$ & $22.5 \mathrm{~g}-\mathrm{o}$ & $18.1 \mathrm{~m}-\mathrm{u}$ & $13.8 \mathrm{t}-\mathrm{x}$ & $9.3 x y$ & 18.5CD \\
\hline Cs2 & $5.4 \mathrm{f}$ & $5.4 \mathrm{f}$ & $4.4 \mathrm{jk}$ & $2.4 \mathrm{t}$ & $1.4 \mathrm{w}$ & $3.8 \mathrm{~F}$ & 21.6i-p & $23.4 \mathrm{f}-\mathrm{m}$ & $16.2 \mathrm{q}-\mathrm{v}$ & $15.3 \mathrm{~s}-\mathrm{V}$ & 9.9wxy & 17.3D \\
\hline Cs3 & $4.3 \mathrm{k}$ & $3.6 n$ & $2.8 \mathrm{r}$ & $1.4 \mathrm{w}$ & $1.7 \mathrm{v}$ & $2.8 \mathrm{H}$ & $34.9 \mathrm{ab}$ & $27.9 \mathrm{c}-\mathrm{g}$ & $20.9 \mathrm{j}-\mathrm{r}$ & $17.6 \mathrm{n}-\mathrm{v}$ & $1.1 \mathrm{z}$ & $20.5 B C$ \\
\hline Cs4 & $4.4 \mathrm{jk}$ & $4.4 \mathrm{jk}$ & $3.9 \mathrm{~m}$ & $3.9 \mathrm{~m}$ & $2.8 q \mathrm{qr}$ & $3.9 \mathrm{E}$ & 21.9h-o & $24.4 \mathrm{~d}-\mathrm{k}$ & $20.3 \mathrm{j}-\mathrm{s}$ & $15.1 \mathrm{~s}-\mathrm{w}$ & $1.6 z$ & 16.7D \\
\hline Cs5 & $5.8 \mathrm{e}$ & $4.4 \mathrm{jk}$ & $2.6 \mathrm{~s}$ & $1.5 \mathrm{w}$ & $1.5 \mathrm{w}$ & $3.2 \mathrm{G}$ & $31.6 b c$ & $27.1 \mathrm{c}-\mathrm{h}$ & $22.7 \mathrm{~g}-\mathrm{o}$ & $16.5 \mathrm{p}-\mathrm{v}$ & $7.0 \mathrm{y}$ & $21.0 \mathrm{AB}$ \\
\hline Cs6 & 5.9de & $6.0 \mathrm{~d}$ & $6.5 \mathrm{ab}$ & $6.6 \mathrm{a}$ & $6.3 c$ & $6.2 \mathrm{~A}$ & $27.3 c-h$ & $29.5 \mathrm{bcd}$ & $23.6 \mathrm{e}-1$ & $21.4 \mathrm{i}-\mathrm{q}$ & $15.1 \mathrm{~s}-\mathrm{w}$ & $23.4 \mathrm{~A}$ \\
\hline Cs 7 & $4.4 \mathrm{jk}$ & 5.9de & $6.4 b c$ & $3.2 \mathrm{o}$ & $3.0 \mathrm{p}$ & $4.6 \mathrm{C}$ & $38.7 \mathrm{a}$ & $28.4 c-f$ & $19.8 \mathrm{j}-\mathrm{s}$ & $15.0 \mathrm{~s}-\mathrm{w}$ & $9.4 x y$ & $22.3 \mathrm{AB}$ \\
\hline Cs8 & $5.2 \mathrm{~g}$ & $5.2 \mathrm{fg}$ & $5.3 \mathrm{fg}$ & $4.8 \mathrm{~h}$ & $4.6 \mathrm{i}$ & $5.0 \mathrm{~B}$ & $22.5 \mathrm{~g}-\mathrm{o}$ & $21.5 \mathrm{i}-\mathrm{q}$ & $24.5 \mathrm{~d}-\mathrm{k}$ & $17.4 \mathrm{o}-\mathrm{V}$ & $15.6 \mathrm{r}-\mathrm{v}$ & $20.3 \mathrm{BC}$ \\
\hline Cs9 & 4.21 & $4.5 \mathrm{ij}$ & $4.3 \mathrm{k}$ & $2.0 \mathrm{u}$ & $1.1 \mathrm{x}$ & $3.2 \mathrm{G}$ & $24.5 \mathrm{~d}-\mathrm{j}$ & $22.3 \mathrm{~h}-\mathrm{o}$ & $18.31-u$ & $13.1 \mathrm{u}-\mathrm{x}$ & $9.1 x y$ & $17.5 \mathrm{D}$ \\
\hline Cs10 & $6.4 b c$ & $4.4 \mathrm{jk}$ & $3.9 \mathrm{~m}$ & $3.6 n$ & $2.9 \mathrm{pq}$ & $4.2 \mathrm{D}$ & $31.0 \mathrm{bc}$ & $26.5 c-i$ & $22.9 \mathrm{~g}-\mathrm{n}$ & $19.1 \mathrm{k}-\mathrm{t}$ & $12.3 \mathrm{v}-\mathrm{y}$ & $22.4 \mathrm{AB}$ \\
\hline Mean & $5.0 \mathrm{~A}$ & $4.8 \mathrm{~B}$ & $4.3 \mathrm{C}$ & $3.1 \mathrm{D}$ & $2.7 \mathrm{E}$ & & $28.3 \mathrm{~A}$ & $25.4 \mathrm{~B}$ & $20.7 \mathrm{C}$ & $16.4 \mathrm{D}$ & $9.0 \mathrm{E}$ & \\
\hline LSD & \multicolumn{6}{|c|}{ Drought $(0.04)$, Isolate $(0.06)$, Drought* Isolate $(0.13)$} & \multicolumn{6}{|c|}{ Drought (1.71), Isolate (2.41), Drought* Isolate $(5.40)$} \\
\hline
\end{tabular}


identified as most water deficit stress tolerant among the tested bacterial isolates.

The bacterial isolates from the stem part of chickpea showed significant decrease in the OD value and cell count with increase in the intensity of PEG induced drought i.e. -0.05 to -2.23 MPa (Table 3). The isolates Cs6 and Cs8 showed significantly higher OD values among all bacterial isolates at all water deficit stress levels $(-0.65,-1.57,-2.17$ and -2.23 $\mathrm{MPa}$ ) followed by $\mathrm{Cs} 7$ which also remained prominent for its OD at $-0.65,-1.57$, and $-2.23 \mathrm{MPa}$. At $-2.17 \mathrm{MPa}$, bacterial isolate Cs4 was also a prominent fellow for its higher OD value along with Cs6 and Cs8. For cell count, Cs6 was most prominent with higher number of cells at $-0.65,-1.57,-2.17$ and -2.23 $\mathrm{MPa}$ as compared to other bacterial isolates. Bacterial isolate Cs10 was following Cs6 with its prominence in cell count at $-1.57,-2.17$ and $-2.23 \mathrm{MPa}$. At -1.57 and -2.23 $\mathrm{MPa}$ and $\mathrm{Cs} 8$ also showed prominent cell count along with Cs6 and Cs10. Whereas Cs3 joined Cs6 and Cs7 for prominent cell count at $-0.65 \mathrm{MPa}$ and $\mathrm{Cs} 6$ and $\mathrm{Cs} 10$ at -2.17 $\mathrm{MPa}$. Isolates Cs6, Cs8 and Cs10 were selected as most efficient to survive and flourish under water deficit conditions on behalf of their OD values and cell counts.

Significant decrease in OD values and cell counts of endophytic bacterial isolates from leaf were observed with decrease in water potential from -0.05 to $-2.23 \mathrm{MPa}$ (Table 4). The water potential $-0.05 \mathrm{MPa}$ was considered as control or normal water potential of media for bacterial growth. At -0.65 $\mathrm{MPa}$, bacterial isolates $\mathrm{Cl} 2, \mathrm{Cl} 3$ and $\mathrm{Cl} 6$ were prominent with higher OD values among other bacterial isolates. At -1.57 $\mathrm{MPa}$, bacterial isolates $\mathrm{Cl} 3, \mathrm{Cl} 6$ and $\mathrm{Cl} 8$ shows higher OD values but at $-2.17 \mathrm{MPa} \mathrm{Cl}, \mathrm{Cl} 9$ and $\mathrm{Cl} 10$ showed higher OD values among other bacterial isolates. The OD values of bacteria isolates $\mathrm{Cl} 3, \mathrm{Cl} 7$ and $\mathrm{Cl} 9$ was prominently higher at $-2.23 \mathrm{MPa}$. For cell count the strains $(\mathrm{Cl} 3, \mathrm{Cl}, \mathrm{Cl}),(\mathrm{Cl} 3$, $\mathrm{Cl}$, Cl10), (Cl2, $\mathrm{Cl} 3, \mathrm{Cl})$, and $(\mathrm{Cl1}, \mathrm{Cl} 3, \mathrm{Cl} 7)$ were prominent among other tested bacterial isolates at -0.65 , 1.57, -2.17 and $-2.23 \mathrm{MPa}$, respectively. On behalf of OD values and cell counts data collectively, the bacterial isolates $\mathrm{Cl} 3, \mathrm{Cl} 6$ and $\mathrm{Cl} 7$ were designated as most water deficit stress tolerant.

Table 4. Drought tolerance assay of endophytic bacteria isolated from chickpea leaves at different PEG induced osmotic stress levels.

\begin{tabular}{|c|c|c|c|c|c|c|c|c|c|c|c|c|}
\hline \multirow[t]{2}{*}{ Isolates } & \multicolumn{6}{|c|}{ Optical Density (OD) $(n=3)$} & \multicolumn{6}{|c|}{ Cell Count $\left(\mathrm{CFU} \mathbf{m L}^{-1} \times \mathbf{1 0}^{-3}\right)(\mathrm{n}=3)$} \\
\hline & $\begin{array}{l}-0.05 \\
(\mathrm{MPa})\end{array}$ & $\begin{array}{c}-0.65 \\
(\mathrm{MPa})\end{array}$ & $\begin{array}{c}-1.57 \\
\text { (MPa) }\end{array}$ & $\begin{array}{c}-2.17 \\
\text { (MPa) }\end{array}$ & $\begin{array}{c}-2.23 \\
\text { (MPa) }\end{array}$ & Mean & $\begin{array}{c}-0.05 \\
(\mathrm{MPa})\end{array}$ & $\begin{array}{c}-0.65 \\
(\mathrm{MPa})\end{array}$ & $\begin{array}{c}-1.57 \\
\text { (MPa) }\end{array}$ & $\begin{array}{c}-2.17 \\
\text { (MPa) }\end{array}$ & $\begin{array}{c}-2.23 \\
(\mathrm{MPa})\end{array}$ & Mean \\
\hline$\overline{\mathrm{Cl}}$ & $4.2 \mathrm{gh}$ & 4.0hi & 2.5 no & $1.6 u v$ & $1.4 \mathrm{v}$ & $2.7 \mathrm{D}$ & $32.2 \mathrm{bcd}$ & $25.8 \mathrm{~d}-\mathrm{j}$ & $21.4 \mathrm{~h}-\mathrm{q}$ & $15.1 \mathrm{q}-\mathrm{t}$ & $6.0 \mathrm{vwx}$ & $20.1 \mathrm{BC}$ \\
\hline $\mathrm{Cl} 2$ & $5.0 \mathrm{e}$ & $4.4 \mathrm{f}$ & 3.01 & $1.4 \mathrm{v}$ & $0.8 \mathrm{wx}$ & $2.9 \mathrm{C}$ & $28.3 \mathrm{c}-\mathrm{g}$ & $24.8 \mathrm{e}-1$ & $9.5 \mathrm{j}-\mathrm{s}$ & $16.3 \mathrm{o}-\mathrm{t}$ & $4.2 \mathrm{wx}$ & 18.6CDE \\
\hline $\mathrm{Cl} 3$ & $6.7 \mathrm{a}$ & $4.8 \mathrm{e}$ & $3.8 \mathrm{i}$ & $1.5 \mathrm{uv}$ & $1.8 \mathrm{st}$ & 3.7A & $37.2 \mathrm{ab}$ & $33.2 \mathrm{bc}$ & $24.5 \mathrm{e}-\mathrm{m}$ & 18.31-s & $8.4 \mathrm{uvw}$ & $24.3 \mathrm{~A}$ \\
\hline $\mathrm{Cl} 4$ & $3.5 \mathrm{j}$ & $3.3 \mathrm{jk}$ & $3.1 \mathrm{kl}$ & $1.9 \mathrm{rs}$ & $1.0 \mathrm{w}$ & $2.5 \mathrm{E}$ & $25.2 \mathrm{e}-\mathrm{k}$ & $22.1 \mathrm{~g}-\mathrm{O}$ & $18.9 \mathrm{k}-\mathrm{s}$ & 13.8 stu & $2.0 \mathrm{wx}$ & $16.4 \mathrm{DE}$ \\
\hline $\mathrm{Cl} 5$ & $3.9 \mathrm{i}$ & $3.5 \mathrm{j}$ & $2.7 \mathrm{mn}$ & $1.5 \mathrm{uv}$ & $0.9 \mathrm{wx}$ & $2.5 \mathrm{E}$ & $28.3 \mathrm{c}-\mathrm{g}$ & $24.8 \mathrm{e}-1$ & $21.7 \mathrm{~h}-\mathrm{p}$ & $15.80-\mathrm{t}$ & $5.0 \mathrm{vwx}$ & 19.1CD \\
\hline $\mathrm{Cl} 6$ & $5.3 \mathrm{~d}$ & $4.5 f$ & $3.4 \mathrm{j}$ & 2.5 no & $1.4 \mathrm{v}$ & $3.4 \mathrm{~B}$ & $30.6 \mathrm{cde}$ & $27.2 \mathrm{c}-\mathrm{i}$ & $23.9 f-n$ & $17.8 n-s$ & $5.1 \mathrm{vwx}$ & $20.9 B C$ \\
\hline $\mathrm{Cl} 7$ & $5.9 \mathrm{c}$ & 4.0hi & 2.5 no & $2.3 \mathrm{pq}$ & $2.1 q r$ & $3.3 \mathrm{~B}$ & $42.0 \mathrm{a}$ & $28.8 \mathrm{c}-\mathrm{f}$ & $18.1 \mathrm{~m}-\mathrm{s}$ & $15.4 \mathrm{p}-\mathrm{t}$ & 8.0uvw & $22.5 \mathrm{AB}$ \\
\hline $\mathrm{Cl} 8$ & $6.4 \mathrm{~b}$ & $4.3 \mathrm{fg}$ & $3.5 \mathrm{j}$ & $2.91 \mathrm{~m}$ & 1.6tu & $3.7 \mathrm{~A}$ & $25.9 \mathrm{~d}-\mathrm{j}$ & 20.8i-r & $21.2 \mathrm{i}-\mathrm{q}$ & $14.4 \mathrm{r}-\mathrm{u}$ & $1.9 \mathrm{wx}$ & 16.8DE \\
\hline $\mathrm{Cl} 9$ & $4.4 \mathrm{fg}$ & $2.5 \mathrm{op}$ & $2.5 \mathrm{op}$ & $3.1 \mathrm{kl}$ & $2.3 \mathrm{pq}$ & $2.9 \mathrm{C}$ & $27.9 \mathrm{c}-\mathrm{h}$ & $18.9 \mathrm{k}-\mathrm{s}$ & $18.31-\mathrm{s}$ & 10.7 tuv & $4.4 \mathrm{vwx}$ & $16.1 \mathrm{E}$ \\
\hline $\mathrm{Cl} 10$ & $3.3 \mathrm{j}$ & $2.7 \mathrm{mn}$ & $2.2 \mathrm{q}$ & $3.8 \mathrm{i}$ & $0.7 \mathrm{x}$ & $2.5 \mathrm{E}$ & 31.0b-e & $25.1 \mathrm{e}-\mathrm{k}$ & $22.9 f-n$ & $4.1 w x$ & $0.7 x$ & $16.8 \mathrm{DE}$ \\
\hline Mean & $4.8 \mathrm{~A}$ & $3.8 \mathrm{~B}$ & $2.9 \mathrm{C}$ & $2.2 \mathrm{D}$ & $1.4 \mathrm{E}$ & & $30.8 \mathrm{~A}$ & $25.2 \mathrm{~B}$ & $21.1 \mathrm{C}$ & $14.2 \mathrm{D}$ & $4.6 \mathrm{E}$ & \\
\hline LSD & \multicolumn{12}{|c|}{ Drought $(0.07)$, Isolate (0.10), Drought* Isolate (0.22) $\quad$ Drought (2.07), Isolate (2.92), Drought* Isolate (6.53) } \\
\hline
\end{tabular}

Table 5. Drought tolerance assay of endophytic bacteria isolated from chickpea pods at different PEG induced osmotic stress levels.

\begin{tabular}{|c|c|c|c|c|c|c|c|c|c|c|c|c|}
\hline \multirow[t]{2}{*}{ Isolates } & \multicolumn{6}{|c|}{ Optical Density (OD) $(n=3)$} & \multicolumn{6}{|c|}{ Cell Count $\left(\mathrm{CFU} \mathrm{mL}^{-1} \times \mathbf{1 0}^{-3}\right)(\mathrm{n}=3)$} \\
\hline & $\begin{array}{c}-0.05 \\
\text { (MPa) }\end{array}$ & $\begin{array}{c}-0.65 \\
\text { (MPa) }\end{array}$ & $\begin{array}{c}-1.57 \\
\text { (MPa) }\end{array}$ & $\begin{array}{c}-2.17 \\
\text { (MPa) }\end{array}$ & $\begin{array}{c}-2.23 \\
\text { (MPa) }\end{array}$ & Mean & $\begin{array}{c}-0.05 \\
\text { (MPa) }\end{array}$ & $\begin{array}{c}-0.65 \\
\text { (MPa) }\end{array}$ & $\begin{array}{c}-1.57 \\
\text { (MPa) }\end{array}$ & $\begin{array}{c}-2.17 \\
\text { (MPa) }\end{array}$ & $\begin{array}{c}-2.23 \\
\text { (MPa) }\end{array}$ & Mean \\
\hline Cp1 & $4.1 \mathrm{i}$ & $3.9 \mathrm{j}$ & $3.41 \mathrm{~m}$ & $2.5 q$ & $1.3 \mathrm{u}$ & $3.1 \mathrm{~F}$ & $31.2 \mathrm{~cd}$ & $24.5 \mathrm{f}-\mathrm{i}$ & $16.8 \mathrm{jk}$ & $5.4 n-r$ & 2.6pqr & 16.1DE \\
\hline $\mathrm{Cp} 2$ & $5.0 f$ & $4.5 \mathrm{~h}$ & $3.5 \mathrm{kl}$ & $3.5 \mathrm{klm}$ & $0.9 \mathrm{w}$ & $3.5 \mathrm{E}$ & $38.4 \mathrm{ab}$ & $30.4 \mathrm{cde}$ & $16.2 \mathrm{jk}$ & 2.3pqr & $1.2 \mathrm{r}$ & 17.7CDE \\
\hline Cp3 & $6.7 \mathrm{a}$ & $6.7 \mathrm{a}$ & $4.8 \mathrm{~g}$ & $3.5 \mathrm{kl}$ & $1.8 \mathrm{t}$ & 4.7A & $41.9 \mathrm{a}$ & $35.5 b c$ & $25.2 \mathrm{e}-\mathrm{h}$ & $15.6 \mathrm{jkl}$ & $9.4 \mathrm{mno}$ & $25.5 \mathrm{~A}$ \\
\hline $\mathrm{Cp} 4$ & $3.5 \mathrm{kl}$ & $3.41 \mathrm{~m}$ & 2.90 & $2.0 \mathrm{~s}$ & $0.9 \mathrm{w}$ & $2.6 \mathrm{G}$ & $35.9 \mathrm{bc}$ & $27.1 \mathrm{def}$ & $16.9 \mathrm{jk}$ & $5.1 \mathrm{n}-\mathrm{r}$ & $0.6 \mathrm{r}$ & 17.1DE \\
\hline $\mathrm{Cp} 5$ & $3.8 \mathrm{j}$ & $3.51 \mathrm{~m}$ & $2.7 \mathrm{p}$ & $1.4 \mathrm{u}$ & $1.1 \mathrm{v}$ & $2.5 \mathrm{G}$ & $35.2 \mathrm{bc}$ & $26.5 \mathrm{def}$ & $16.1 \mathrm{jk}$ & $1.8 \mathrm{qr}$ & $0.7 \mathrm{r}$ & 16.0DE \\
\hline Cp6 & $5.4 \mathrm{~d}$ & $5.6 \mathrm{~d}$ & $4.5 \mathrm{~h}$ & $2.7 \mathrm{p}$ & $1.3 \mathrm{u}$ & $3.9 \mathrm{C}$ & $28.3 \mathrm{def}$ & $19.5 \mathrm{ij}$ & $17.6 \mathrm{jk}$ & 7.4nop & $4.8 \mathrm{n}-\mathrm{r}$ & $15.5 \mathrm{E}$ \\
\hline $\mathrm{Cp} 7$ & $5.8 \mathrm{c}$ & $6.0 \mathrm{c}$ & $3.41 \mathrm{~m}$ & $2.2 \mathrm{r}$ & $2.1 \mathrm{rs}$ & $3.9 \mathrm{C}$ & $37.0 \mathrm{ab}$ & $24.4 \mathrm{f}-\mathrm{i}$ & 19.8hij & $10.01 \mathrm{mn}$ & $7.4 \mathrm{n}-\mathrm{q}$ & $19.7 \mathrm{BC}$ \\
\hline Cp8 & $6.5 b$ & $5.3 \mathrm{e}$ & $4.6 \mathrm{~h}$ & 2.90 & $1.7 \mathrm{t}$ & $4.2 \mathrm{~B}$ & $35.9 \mathrm{bc}$ & $20.5 \mathrm{~g}-\mathrm{j}$ & $17.2 \mathrm{jk}$ & $8.4 \mathrm{mno}$ & $1.6 r$ & 16.7DE \\
\hline Cp9 & $4.4 \mathrm{~h}$ & $4.6 \mathrm{~h}$ & $4.4 \mathrm{~h}$ & $3.1 \mathrm{n}$ & $2.2 \mathrm{r}$ & $3.8 \mathrm{D}$ & 37.9ab & $25.6 \mathrm{~d}-\mathrm{g}$ & $18.3 \mathrm{jk}$ & $9.1 \mathrm{mno}$ & $0.7 \mathrm{r}$ & 18.3BCD \\
\hline Cp10 & $3.41 \mathrm{~m}$ & $3.3 \mathrm{~m}$ & $3.9 \mathrm{j}$ & $3.6 \mathrm{k}$ & $3.41 \mathrm{~m}$ & $3.5 \mathrm{E}$ & $39.3 \mathrm{ab}$ & $27.1 \mathrm{def}$ & $18.6 \mathrm{jk}$ & $13.5 \mathrm{klm}$ & $4.00-r$ & $20.5 B$ \\
\hline Mean & $4.9 \mathrm{~A}$ & $4.7 \mathrm{~B}$ & $3.8 \mathrm{C}$ & $2.8 \mathrm{D}$ & $1.7 \mathrm{E}$ & & $36.1 \mathrm{~A}$ & 26.1B & $18.3 \mathrm{C}$ & 7.9D & $3.3 \mathrm{E}$ & \\
\hline LSD & \multicolumn{6}{|c|}{ Drought $(0.05)$, Isolate $(0.07)$, Drought* Isolate $(0.16)$} & \multicolumn{6}{|c|}{ Drought (1.77), Isolate (2.51), Drought* Isolate (5.60) } \\
\hline
\end{tabular}


Table 6. Performance of endophytic bacteria to promote shoot/root length $(\mathrm{cm})$ and dry mass under water deficit axenic conditions.

\begin{tabular}{|c|c|c|c|c|c|c|c|c|}
\hline \multirow[b]{2}{*}{ Isolates } & \multicolumn{4}{|c|}{ Root length $(\mathrm{cm})(\mathrm{n}=3)$} & \multicolumn{4}{|c|}{ Shoot length $(\mathrm{cm})(\mathrm{n}=3)$} \\
\hline & No PEG & $15 \%$ PEG & 30\%PEG & Mean & No PEG & $15 \%$ PEG & 30\%PEG & Mean \\
\hline Control & $14.6 \mathrm{~g}-\mathrm{k}$ & $12.5 \mathrm{~m}-\mathrm{p}$ & $9.2 \mathrm{rs}$ & $12.1 \mathrm{G}$ & $15.2 \mathrm{~g}-\mathrm{m}$ & $13.0 \mathrm{opq}$ & $11.2 \mathrm{rst}$ & $13.2 \mathrm{~F}$ \\
\hline $\mathrm{Cr} 2$ & $19.7 \mathrm{a}$ & $15.6 \mathrm{e}-\mathrm{h}$ & $10.5 \mathrm{qr}$ & 15.2 CDE & $19.0 \mathrm{a}$ & $16.2 \mathrm{e}-\mathrm{i}$ & $11.0 \mathrm{rst}$ & $15.4 \mathrm{CDE}$ \\
\hline $\mathrm{Cr} 3$ & $19.0 \mathrm{ab}$ & $14.1 \mathrm{~h}-1$ & $11.7 \mathrm{pq}$ & 14.9 DEF & $18.7 \mathrm{ab}$ & $14.11-0$ & $12.3 \mathrm{pqr}$ & $15.1 \mathrm{DE}$ \\
\hline $\mathrm{Cr} 10$ & $14.7 \mathrm{~g}-\mathrm{j}$ & $13.0 \mathrm{k}-\mathrm{p}$ & $15.2 \mathrm{e}-\mathrm{h}$ & $14.3 \mathrm{~F}$ & $15.1 \mathrm{~h}-\mathrm{n}$ & $14.0 \mathrm{mno}$ & $14.7 \mathrm{j}-\mathrm{n}$ & $14.6 \mathrm{E}$ \\
\hline Cs6 & $13.5 \mathrm{i}-\mathrm{O}$ & $12.0 \mathrm{n}-\mathrm{q}$ & $8.5 \mathrm{~s}$ & $11.3 \mathrm{G}$ & $14.11-0$ & $11.4 \mathrm{rs}$ & $10.3 \mathrm{st}$ & $11.9 \mathrm{G}$ \\
\hline Cs8 & $18.1 \mathrm{abc}$ & $15.5 \mathrm{e}-\mathrm{h}$ & $14.0 \mathrm{~h}-\mathrm{m}$ & $15.9 \mathrm{ABC}$ & $18.5 \mathrm{ab}$ & $16.5 \mathrm{c}-\mathrm{g}$ & $15.3 \mathrm{~g}-\mathrm{m}$ & $16.8 \mathrm{~A}$ \\
\hline Cs 10 & $16.5 \mathrm{def}$ & $17.6 \mathrm{bcd}$ & $15.0 \mathrm{f}-\mathrm{i}$ & $16.3 \mathrm{AB}$ & $16.8 \mathrm{c}-\mathrm{f}$ & $17.9 \mathrm{abc}$ & $13.0 \mathrm{opq}$ & $15.9 \mathrm{BC}$ \\
\hline $\mathrm{Cl} 3$ & $13.7 \mathrm{i}-\mathrm{m}$ & $11.8 \mathrm{pq}$ & $8.9 \mathrm{~s}$ & $11.6 \mathrm{G}$ & 13.7 nop & $12.2 \mathrm{qr}$ & $9.9 \mathrm{tu}$ & $11.9 \mathrm{G}$ \\
\hline $\mathrm{Cl} 6$ & $18.1 \mathrm{abc}$ & $13.0 \mathrm{k}-\mathrm{p}$ & $12.61-\mathrm{p}$ & $14.6 \mathrm{EF}$ & $17.8 \mathrm{a}-\mathrm{d}$ & $14.0 \mathrm{mno}$ & $12.9 \mathrm{opq}$ & $14.9 \mathrm{DE}$ \\
\hline $\mathrm{Cl} 7$ & $13.6 \mathrm{i}-\mathrm{n}$ & $11.9 \mathrm{opq}$ & $8.7 \mathrm{~s}$ & $11.4 \mathrm{G}$ & $14.3 \mathrm{k}-\mathrm{o}$ & $12.3 \mathrm{pqr}$ & $8.7 \mathrm{u}$ & $11.7 \mathrm{G}$ \\
\hline $\mathrm{Cp} 3$ & $15.0 \mathrm{f}-\mathrm{i}$ & $16.0 \mathrm{efg}$ & $15.8 \mathrm{efg}$ & 15.6 BCD & $17.3 \mathrm{~b}-\mathrm{e}$ & $16.4 \mathrm{~d}-\mathrm{h}$ & $16.0 \mathrm{e}-\mathrm{j}$ & $16.6 \mathrm{AB}$ \\
\hline Cp7 & $18.1 \mathrm{abc}$ & $14.2 \mathrm{~h}-\mathrm{k}$ & $17.6 \mathrm{bcd}$ & $16.6 \mathrm{~A}$ & $18.6 \mathrm{ab}$ & $14.9 \mathrm{i}-\mathrm{n}$ & $16.3 \mathrm{e}-\mathrm{i}$ & $16.6 \mathrm{AB}$ \\
\hline Cp10 & $14.8 \mathrm{ghi}$ & $13.2 \mathrm{j}-\mathrm{p}$ & $16.7 \mathrm{cde}$ & 14.9 DEF & $15.5 \mathrm{f}-1$ & $15.9 \mathrm{f}-\mathrm{j}$ & $15.6 \mathrm{f}-\mathrm{k}$ & $15.7 \mathrm{CD}$ \\
\hline Mean & $16.1 \mathrm{~A}$ & $13.9 \mathrm{~B}$ & $12.6 \mathrm{C}$ & & $16.5 \mathrm{~A}$ & 14.5 B & $12.9 \mathrm{C}$ & \\
\hline LSD & \multicolumn{4}{|c|}{$\begin{array}{l}\text { Drought (0.44), Isolate (0.91), } \\
\text { Drought* Isolate (1.57) }\end{array}$} & \multicolumn{4}{|c|}{$\begin{array}{l}\text { Drought }(0.41) \text {, Isolate }(0.82) \text {, } \\
\text { Drought* Isolate }(1.42)\end{array}$} \\
\hline
\end{tabular}

\begin{tabular}{|c|c|c|c|c|c|c|c|c|}
\hline \multirow[b]{2}{*}{ Isolates } & \multicolumn{4}{|c|}{ Root dry weight $(\mathrm{g})(\mathrm{n}=3)$} & \multicolumn{4}{|c|}{ Shoot dry weight $(g)(n=3)$} \\
\hline & No PEG & $15 \%$ PEG & 30\%PEG & Mean & No PEG & 15\%PEG & 30\% PEG & Mean \\
\hline Control & $1.04 \mathrm{c}-\mathrm{g}$ & $0.53 \mathrm{mno}$ & $0.22 \mathrm{p}$ & $0.60 \mathrm{EF}$ & 0.24 e-m & $0.23 \mathrm{~g}-\mathrm{n}$ & $0.181-0$ & $0.22 \mathrm{DE}$ \\
\hline $\mathrm{Cr} 2$ & $1.23 \mathrm{a}-\mathrm{e}$ & $0.97 \mathrm{f}-\mathrm{i}$ & $0.21 \mathrm{p}$ & $0.81 \mathrm{CD}$ & $0.28 \mathrm{~d}-\mathrm{j}$ & $0.30 \mathrm{c}-\mathrm{g}$ & $0.12 \mathrm{opq}$ & $0.23 \mathrm{CDE}$ \\
\hline $\mathrm{Cr} 3$ & $1.28 \mathrm{abc}$ & $0.79 \mathrm{~h}-\mathrm{k}$ & 0.36 op & $0.81 \mathrm{CD}$ & $0.31 \mathrm{~b}-\mathrm{e}$ & $0.22 \mathrm{~h}-\mathrm{n}$ & $0.21 \mathrm{j}-\mathrm{n}$ & $0.25 \mathrm{CD}$ \\
\hline Cr10 & $1.13 \mathrm{c}-\mathrm{g}$ & $0.73 \mathrm{j}-\mathrm{m}$ & $0.78 \mathrm{i}-1$ & $0.88 \mathrm{BC}$ & $0.25 \mathrm{e}-1$ & $0.24 \mathrm{e}-\mathrm{m}$ & $0.25 \mathrm{e}-\mathrm{m}$ & $0.25 \mathrm{CD}$ \\
\hline Cs6 & $0.551-0$ & $0.21 \mathrm{p}$ & $0.21 \mathrm{p}$ & $0.32 \mathrm{G}$ & $0.23 \mathrm{f}-\mathrm{n}$ & 0.18 1-o & $0.06 \mathrm{q}$ & $0.16 \mathrm{~F}$ \\
\hline Cs8 & $1.27 \mathrm{a}-\mathrm{d}$ & $1.15 \mathrm{~b}-\mathrm{g}$ & $0.97 \mathrm{f}-\mathrm{i}$ & $1.13 \mathrm{~A}$ & $0.36 \mathrm{abc}$ & $0.31 \mathrm{~b}-\mathrm{e}$ & $0.24 \mathrm{f}-\mathrm{m}$ & $0.30 \mathrm{AB}$ \\
\hline Cs 10 & $1.20 \mathrm{~b}-\mathrm{f}$ & $1.46 \mathrm{a}$ & 0.38 nop & $1.01 \mathrm{AB}$ & $0.31 \mathrm{~b}-\mathrm{f}$ & $0.30 \mathrm{c}-\mathrm{g}$ & $0.22 \mathrm{i}-\mathrm{n}$ & $0.27 \mathrm{ABC}$ \\
\hline $\mathrm{Cl} 3$ & $1.11 \mathrm{c}-\mathrm{g}$ & 0.37 op & $0.19 \mathrm{p}$ & $0.56 \mathrm{~F}$ & $0.25 \mathrm{e}-1$ & $0.17 \mathrm{mno}$ & 0.16 nop & $0.20 \mathrm{EF}$ \\
\hline $\mathrm{Cl} 6$ & $1.01 \mathrm{e}-\mathrm{i}$ & $0.62 \mathrm{k}-\mathrm{n}$ & 0.48 no & $0.70 \mathrm{DE}$ & $0.35 \mathrm{a}-\mathrm{d}$ & $0.25 \mathrm{e}-\mathrm{m}$ & $0.21 \mathrm{j}-\mathrm{n}$ & $0.27 \mathrm{ABC}$ \\
\hline $\mathrm{Cl} 7$ & $0.551-0$ & $0.21 \mathrm{p}$ & $0.17 \mathrm{p}$ & $0.31 \mathrm{G}$ & $0.22 \mathrm{~h}-\mathrm{n}$ & $0.19 \mathrm{k}-\mathrm{o}$ & $0.09 \mathrm{pq}$ & $0.17 \mathrm{~F}$ \\
\hline Cp3 & $1.13 \mathrm{c}-\mathrm{g}$ & $1.06 \mathrm{c}-\mathrm{g}$ & $1.03 \mathrm{~d}-\mathrm{h}$ & $1.07 \mathrm{~A}$ & $0.41 \mathrm{a}$ & $0.29 \mathrm{c}-\mathrm{i}$ & $0.24 \mathrm{f}-\mathrm{m}$ & $0.31 \mathrm{~A}$ \\
\hline $\mathrm{Cp} 7$ & $1.37 \mathrm{ab}$ & $0.94 \mathrm{~g}-\mathrm{j}$ & $1.04 \mathrm{c}-\mathrm{g}$ & $1.12 \mathrm{~A}$ & $0.38 \mathrm{ab}$ & $0.25 \mathrm{e}-1$ & 0.18 1-o & $0.27 \mathrm{ABC}$ \\
\hline Cp10 & $1.21 \mathrm{~b}-\mathrm{f}$ & $1.06 \mathrm{c}-\mathrm{g}$ & $1.04 \mathrm{c}-\mathrm{g}$ & $1.10 \mathrm{~A}$ & $0.31 \mathrm{~b}-\mathrm{f}$ & $0.26 \mathrm{e}-\mathrm{k}$ & $0.24 \mathrm{f}-\mathrm{m}$ & $0.27 \mathrm{BC}$ \\
\hline Mean & $1.08 \mathrm{~A}$ & $0.78 \mathrm{~B}$ & $0.54 \mathrm{C}$ & & $0.30 \mathrm{~A}$ & $0.25 \mathrm{~B}$ & $0.18 \mathrm{C}$ & \\
\hline LSD & $\begin{array}{l}\text { Drought }(0.0 \\
\text { Drought* Iss }\end{array}$ & $\begin{array}{l}\text { solate }(0.1 \\
(0.24)\end{array}$ & & & Drought* I & $\begin{array}{l}\text { solate }(0 . \\
(0.07)\end{array}$ & & \\
\hline
\end{tabular}

*PEG: Polyethylene glycol

The cell count and OD values of the bacterial isolates from pods (Table 5) showed significant decrease with increase in PEG induced water deficit conditions (i.e. $-0.05,-0.65,-1.57$, -2.17 and $-2.23 \mathrm{MPa}$ ). At $-0.65 \mathrm{MPa}, \mathrm{Cp} 3, \mathrm{Cp} 6$ and $\mathrm{Cp} 7$ were most prominent for OD while $\mathrm{Cp} 2, \mathrm{Cp} 3, \mathrm{Cp} 4$ and $\mathrm{Cp} 10$ showed significantly higher cell count. Bacterial isolates $\mathrm{Cp} 3$, Cp6 and Cp8 showed higher OD at -1.57 MPa. At -2.17 and $2.23 \mathrm{MPa}$, bacterial isolates (Cp2, Cp3, Cp10) and (Cp7, Cp9, $\mathrm{Cp} 10$ ), respectively, remained prominent for OD among other bacterial isolates. Bacterial isolates $\mathrm{Cp} 3, \mathrm{Cp} 7$ and $\mathrm{Cp} 10$ showed significantly higher cell count at -1.57 and $-2.17 \mathrm{MPa}$. At $-2.23 \mathrm{MPa}$, significantly higher cell counts were recorded for $\mathrm{Cp} 3, \mathrm{Cp} 6$ and $\mathrm{Cp} 7$. Overall analysis of the OD values and cell count data, the bacterial isolates $\mathrm{Cp} 3, \mathrm{Cp} 7$ and $\mathrm{Cp} 10$ were selected as most efficient water deficit stress abiding bacterial strains among other bacterial isolates.
Plant growth promoting activity of endophytic bacteria under water deficit stress: Water deficit stress tolerant bacterial isolates $(\mathrm{Cr} 2, \mathrm{Cr} 3, \mathrm{Cr} 10, \mathrm{Cs} 6, \mathrm{Cs} 8, \mathrm{Cs} 10, \mathrm{Cl} 3, \mathrm{Cl} 6$, $\mathrm{Cl} 7, \mathrm{Cp} 3, \mathrm{Cp} 7$ and $\mathrm{Cp} 10$ ) selected from OD values and cell counts at various PEG-6000 induced water potential levels were tested for their potential as plant growth promoting bacteria. Chickpea seedling growth was observed with the inoculation of endophytic isolates $(\mathrm{Cr} 2, \mathrm{Cr} 3, \mathrm{Cr} 10, \mathrm{Cs} 6, \mathrm{Cs} 8$, $\mathrm{Cs} 10, \mathrm{Cl} 3, \mathrm{Cl} 6, \mathrm{Cl} 7, \mathrm{Cp} 3, \mathrm{Cp} 7$ and $\mathrm{Cp} 10)$ under normal (No PEG) and water deficit stress (PEG 15 and 30\%) situations. Water deficit stress caused significant decrease in the length (21\%) and dry biomass of root (50\%) and shoot (40\%) (Table 6).

Under normal conditions, inoculation with $\mathrm{Cr} 2, \mathrm{Cr} 3, \mathrm{Cs} 8$, $\mathrm{Cs} 10, \mathrm{Cl} 6$, and $\mathrm{Cp} 7$ showed a significant increase in root length in comparison to un-inoculated control (Table 6). At 
15\% PEG, Cr2, Cr3, Cs8, Cs10, Cp3, and Cp7 significantly increased the root length as compared to respective uninoculated control. At 30\% PEG, Cr3, Cr10, Cs8, Cs10, Cl6, $\mathrm{Cp} 3, \mathrm{Cp} 7$ and $\mathrm{Cp} 10$ inoculation significantly increased root length over un-inoculated control. However, maximum root length was recorded by inoculation with $\mathrm{Cr} 2, \mathrm{Cs} 10, \mathrm{Cp} 7$ at no PEG, 15 and 30\% PEG, respectively. Inoculation of Cs8, $\mathrm{Cs} 10$ and $\mathrm{Cp} 7$ appeared to be the most efficient for increasing root length $(51 \%, 63 \%$, and $90 \%$, respectively) as a whole.

Shoot length (Table 6) was increased significantly by the inoculation with $(\mathrm{Cr} 2, \mathrm{Cr} 3, \mathrm{Cs} 8, \mathrm{Cs} 10, \mathrm{Cl} 3, \mathrm{Cl} 6, \mathrm{Cp} 3$ and $\mathrm{Cp} 7, \mathrm{Cr} 2, \mathrm{Cs} 8, \mathrm{Cs} 10, \mathrm{Cp} 3, \mathrm{Cp} 7$ and $\mathrm{Cp} 10)$, and (Cr10, Cs8, $\mathrm{Cs} 10, \mathrm{Cl} 6, \mathrm{Cp} 3, \mathrm{Cp} 7$ and $\mathrm{Cp} 10)$ over respective un-inoculated controls at no PEG, 15 and 30\% PEG, respectively. Maximum shoot length at no PEG, 15 and 30\% PEG was observed due to the inoculation of $\mathrm{Cr} 2, \mathrm{Cs} 10$ and $\mathrm{Cp} 7$, respectively. Whereas overall efficiency of Cs8, Cp7 and Cp10 inoculation was prominent among other bacterial isolates for improving shoot growth.

Root dry weight (Table 6) was significantly increased only by the inoculation of $\mathrm{Cp} 7$ over un-inoculated control at normal conditions except $\mathrm{Cs} 6$ and $\mathrm{Cl} 7$ which significantly decreased it. At 15\% PEG, Cs10 inoculation showed maximum root dry biomass but all other bacterial isolates except $\mathrm{Cr} 3, \mathrm{Cl} 3$ and Cl6 remained statistically different from un-inoculated control. The bacterial isolates from pods $(\mathrm{Cp} 3, \mathrm{Cp} 7, \mathrm{Cp} 10)$ showed maximum and significant increase in the root dry biomass over un-inoculated control at 30\% PEG followed by Cs8, Cr10 and Cl6, respectively. Looking into the main effects of endophytic bacteria inoculation, bacterial isolates from roots $(\mathrm{Cr} 2, \mathrm{Cr} 3, \mathrm{Cr} 10)$, pods $(\mathrm{Cp} 3, \mathrm{Cp} 7, \mathrm{Cp} 10)$ and stem (Cs8, Cs10) showed significant increase in root dry biomass as compared to un-inoculated control whereas bacterial isolates from leaf $(\mathrm{Cl} 3, \mathrm{Cl} 6)$ remained statistically at par with control and $\mathrm{Cs} 6$ and $\mathrm{Cl} 7$ reduced the root dry biomass.

Shoot dry biomass (Table 6) was significantly increased over un-inoculated control by $\mathrm{Cs} 8, \mathrm{Cl} 6, \mathrm{Cp} 3$ and $\mathrm{Cp} 7$ under normal conditions. Only Cs8 inoculated seedlings showed a significant increase over un-inoculated control at 15\% PEG whereas other all inoculations remained statistically similar to control. At 30\% PEG, inoculation with endophytic bacteria remained similar to un-inoculated control for shoot dry biomass. However, $\mathrm{Cs} 6$ and $\mathrm{Cl} 7$ inoculation reduced the shoot dry biomass at 30\% PEG as compared to un-inoculated control. The main effect of inoculation showed no effect of isolates from roots but a significant improvement with isolates from pods.

As a whole, bacterial isolates $\mathrm{Cs} 8$ and $\mathrm{Cp} 7$ inoculation showed significant improvements in root/shoot length and root/shoot dry biomass as compared to un-inoculated control followed by Cs10 (increased root length, root/shoot dry biomass) and $\mathrm{Cp} 3$ (increased shoot length, root/shoot dry biomass) and remained prominent among the inoculated isolates.

Dry matter stress tolerance index (Figure 1) was significantly improved by the inoculation of $\mathrm{Cr} 2, \mathrm{Cs} 8, \mathrm{Cs} 10, \mathrm{Cl} 3, \mathrm{Cp} 3$ and Cp10 under 15\% PEG induced water deficit stress in comparison to un-inoculated control. At 30\% PEG induced water deficit stress, $\mathrm{Cr} 10, \mathrm{Cs} 8, \mathrm{Cp} 3$ and $\mathrm{Cp} 10$ significantly improved the dry matter stress tolerance index as compared to un-inoculated control. Bacterial isolates $\mathrm{Cs} 8, \mathrm{Cp} 3$ and Cp10 were most efficient among other inoculated bacterial isolates for improving dry matter stress tolerance index.

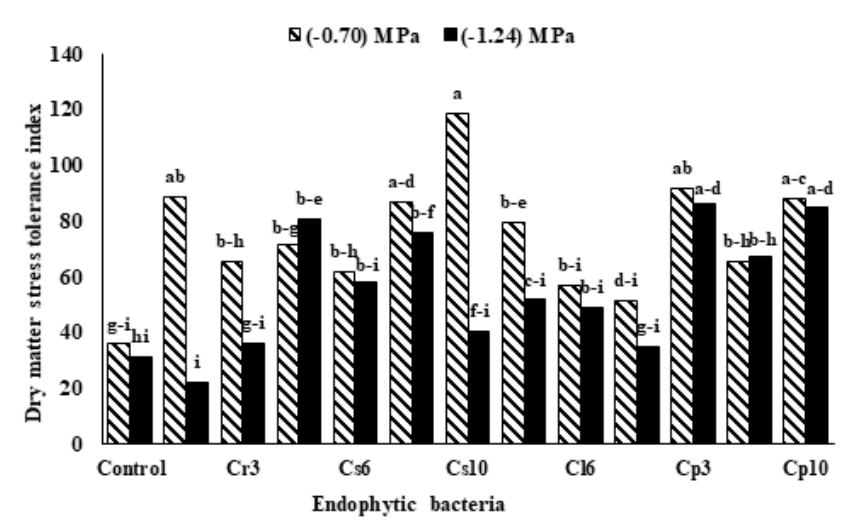

Figure 1. Performance of endophytic bacteria to promote dry matter stress tolerance index under water deficit axenic conditions. $(n=3)$.

Characterization of selected endophytic bacteria: The bacterial isolates from stem $\mathrm{Cs} 8, \mathrm{Cs} 10$ belonged to Ochrobactrum genius whereas the bacterial isolates from pods (Cp3, Cp7) were Stenotrophomonas (Table 7). All the bacterial strains were capable to produce catalase, oxidase and exopolysaccharides. Endophytic bacterial isolates from stem had higher aggregation capability (Cs8, Cs10; 4.40\%, 4.27\%,

Table 7. Characterization of endophytic bacteria.

\begin{tabular}{lllll}
\hline Characters of different endophytic isolate & Cs8 & Cs10 & Cp3 & Cp7 \\
\hline Aggregation assay & $4.40 \%$ & $4.27 \%$ & $3.45 \%$ & $3.12 \%$ \\
Auxin production (Without L-TRP) & $3.23 \mathrm{mg} \mathrm{mL}^{-1}$ & $2.98 \mathrm{mg} \mathrm{m}^{-1}$ & $3.60 \mathrm{mg} \mathrm{mL}^{-1}$ & $3.78 \mathrm{mg} \mathrm{mL}^{-1}$ \\
(With L-TRP) & $19.89 \mathrm{mg} \mathrm{mL}^{-1}$ & $21.29 \mathrm{mg} \mathrm{m}^{-1}$ & $25.67 \mathrm{mg} \mathrm{mL}^{-1}$ & $29.53 \mathrm{mg} \mathrm{mL}^{-1}$ \\
Catalase & +++ & ++ & ++ & + \\
Oxidase & + & + & + & + \\
Exopolysaccharides & +++ & ++ & ++ & ++ \\
\hline
\end{tabular}


respectively) than the bacterial isolates from pods $(\mathrm{Cp} 3, \mathrm{Cp} 7$; $3.45 \%, 3.12 \%$, respectively). Auxin production in the absence of L-tryptophan was higher by $\mathrm{Cp} 7\left(3.78 \mathrm{mg} \mathrm{mL}^{-1}\right)$ followed by Cp3 (3.60 mg mL $\left.\mathrm{mL}^{-1}\right)$, Cs8 (3.23 $\left.\mathrm{mg} \mathrm{mL}^{-1}\right)$ and Cs10 (2.98 $\left.\mathrm{mg} \mathrm{mL}^{-1}\right)$, respectively. In the presence of L-tryptophan, production of auxin was increased in all the isolates as Cs8, Cs10, Cp3, and Cp7, 19.89, 21.29, 25.67 and $29.53 \mathrm{mg} \mathrm{mL}^{-1}$, respectively.

\section{DISCUSSION}

Water deficit stress is main constraint to the survival of plant growth promoting bacteria in the rhizosphere (Vurukonda et al., 2016). Whereas the plant have lower osmotic potential as compared to rhizosphere in order to uptake water and nutrients for their growth and development (Hsiao, 1979; Nobel, 1999). Endophytic bacteria identified in this study are capable to survive and grow at substantially low osmotic potential $(-2.23 \mathrm{MPa})$ isolated from different tissues (root, stem, leaves, pods) of chickpea. Bacteria show varying capacity to adapt osmotic stress conditions (Naz et al., 2009; Sgroy et al., 2009) depending on their genetic diversity and makeup (Trabelsi et al., 2009). Survivability of bacteria might be enhanced by different mechanisms like osmoregulation with the production and accumulation of compatible osmolytes (trehalose, ectoine, glycine betaine) and extracellular proteases and change in cell morphology (Busse and Bottomley, 1989; Smith and Smith, 1989; Das et al., 2015). Accumulation of glutamate and ionic potassium inside the bacterial cell maintains the water relation and safeguard it from severe osmotic stress (Botsford and Lewis, 1990). Bacterial ability to produce exopolysaccharides, oxidase and catalase helps them to sustain under drought through the development of multicellular layer (biofilm) and scavenging reactive oxygen species to avoid cell/ membrane/ nucleic acid rupture (Goyal et al., 1986; Boumahdi et al., 1999; Vanderlinde et al., 2010). Therefore, amino acid, proline, soluble sugars and exopolysaccharides producing ability of bacteria are regarded as indicators of drought tolerance (Vardharajula et al., 2011). Possibility for water deficit stress adaptability by endophytic bacteria is certain due to their niches inside the different tissues of plants where osmotic potential likely to be at the lowest in comparison to the rhizosphere. Therefore, these water deficit stress tolerant endophytes could be a potential resource for improving plant growth under drought.

Top three strains capable to survive under PEG induced water deficit stress were selected from each niche (root, stem, leaves, pods) and tested for improving the growth of chickpea seedlings under drought in gnotobiotic conditions. Though, growth of seedlings was reduced significantly due to water deficit stress as compared to control. However, inoculation with selected bacteria significantly improved the root/shoot length and biomass over un-inoculated plants. Drought disrupts the normal functioning of plant varying their physiological and biochemical responses, whereas, plant growth promoting bacteria induce certain plant functioning to ameliorate/reduce the stress impact (Yang et al., 2009; Vardharajula et al., 2011). Improvement in growth and biomass of chickpea seedlings under water limited conditions in this study might be due to the ability of endophytic strains to produce auxins (for increased root growth to increase exploring area), exopolysaccharides (to increase water and nutrient holding capacity of rhizosphere). Moreover, the production of siderophores, nutrient solubilization, and plant growth hormones like gibberellin and cytokinins would have participated in improving water deficit stress tolerance and improved growth of chickpea seedlings (Hallmann et al., 1997; Rosenblueth and Martinez-Romero, 2006; Mitter et al., 2013). Bacteria having the ability to colonize roots at a higher rate can improve drought tolerance of plants through increasing $\mathrm{P}$ nutrition and vigor of the plant under stress (Arachevaleta et al., 1989; Hallmann et al., 1997; Verma et al., 2001; Azevedo and Araujo, 2003; Wakelin et al., 2004).

Conclusions: Endophytic bacterial isolates from stem and pods of chickpea seemed to be the prominent among the inoculants. These isolates improve the growth of chickpea seedlings normal as well as in water deficit conditions. Role of these endophytic bacteria for promoting rhizobia-legume symbiosis may also be explored in future.

Acknowledgement: Financial and technical support for this study was provided by Soil Microbiology and Biochemistry Lab, Institute of Soil and Environmental Sciences, University of Agriculture Faisalabad, Pakistan.

\section{REFERENCES}

Arachevaleta, M., C.W. Bacon, C.S. Hoveland and D.E. Radcliffe. 1989. Effect of the tall fescue endophyte on plant response to environmental stress. Agron. J. 81:8390.

Ashraf, M., S.H. Berge and O.T. Mahmood. 2004. Inoculating Chickpea seedling with exopolysaccharide-producing bacteria restricts sodium uptake and stimulates plant growth under salt stress. Biol. Fertil. Soils 40:157-162.

Ashraf, M.Y., K. Akhtar, F. Hussain and J. Iqbal. 2006. Screening of different accessions of three potential grass species from Cholistan desert for salt tolerance. Pak. J. Bot. 38:1589-1597.

Azevedo, J.L. and W.L. Araujo. 2003. Genetically modified crops: Environmental and human health concerns. Mutation Res. 544:223-233.

Beattie, G.A. 2007. Plant associated bacteria: survey, molecular phylogeny, genomics and recent advances. In. S.S. Gnanamanickam (ed.), Plant-Associated Bacteria. Springer, New Dehli, India; pp.1-56. 
Botsford, J.L. and T.A. Lewis. 1990. Osmoregulation in Rhizobium meliloti: production of glutamic acid in response to osmotic stress. Appl. Environ. Microbiol. 56:488-494.

Boumahdi, M., P. Mary and J.P. Hornez. 1999. Influence of growth phases and desiccation on the degrees of unsaturation of fatty acids and the survival rates of rhizobia. J. Appl. Microbiol. 87:611-619.

Busse, M.D. and P.J. Bottomley. 1989. Growth and nodulation responses of Rhizobium meliloti to water stress induced by permeating and non-permeating solutes. Appl. Environ. Microbiol. 10:2431-2436.

Das, P., K.K. Nutan, S.L. Singla-Pareek and A. Pareek. 2015. Understanding salinity responses and adopting 'omicsbased' approaches to generate salinity tolerant cultivars of rice. Front. Plant Sci. 6:712.

Dudega, S.S. and R. Giri. 2014. Beneficial properties, colonization, establishment and molecular diversity of endophytic bacteria in legumes and non legumes. Afr. J. Microbiol. Res. 8:1562-1572.

Eevers, N., M. Gielen, A. Sánchez-López, S. Jaspers, J.C. White, J. Vangronsveld and N. Weyens. 2015. Optimization of isolation and cultivation of bacterial endophytes through addition of plant extract to nutrient media. Microb. Biotechnol. 8:707-715.

Egamberdieva, D., S.J. Wirth, V.V. Shurigin, A. Hashem and E.F. Abd Allah. 2017. Endophytic bacteria improve plant growth, symbiotic performance of chickpea (Cicer arietinum L.) and induce suppression of root rot caused by Fusarium solani under salt stress. Front. Microbiol. 8:1887.

Fahad, S., A.A. Bajwa, U. Nazir, S.A. Anjum, A. Farooq, A. Zohaib, S. Sadia, W. Nasim, S. Adkins, S. Saud, M.Z. Ihsan, H. Alharby, C. Wu, D. Wang and J. Huang. 2017. Crop Production under drought and heat stress: Plant responses and management options. Front. Plant Sci. doi.org/10.3389/fpls.2017.01147.

Goyal, V., S. Chetal and H.S. Nainawatee. 1986. Alterations in Rhizobium trifolii catalase under water stress. Folia Microbiol. 31:164-166.

Hallmann, J., A. Quadt-Hallmann, W.F. Mahaffee and J.W. Kloepper. 1997. Bacterial endophytes in agricultural crops. Can. J. Microbiol. 43:895-914.

Hardoim, P.R., L.S.V. Overbeek and J.D.V. Elsas. 2008. Properties of bacterial endophytes and their proposed role in plant growth. Trends Microbiol. 16:463-471.

Hsiao, T.C. 1979. Plant responses to water deficits, efficiency, and drought resistance. Agric. Meteorol. 14:59-84.

Kavamura, V.N., S.N. Santos, J.L. da Silva, M.M. Parma, L.A. Avila, A. Visconti, T.D. Zucchi, R.G. Taketani, F.D. Andreote and I.S.D. Melo. 2013. Screening of Brazilian cacti rhizobacteria for plant growth promotion under drought. Microbiol. Res. 168:183-191.
Long, H.H., D.D. Schmidt and I.T. Baldwin. 2008. Native bacterial endophytes promote host growth in a speciesspecific manner; phytohormone manipulations do not result in common growth responses. PLoS ONE 3:2702.

MacFaddin, J.F. 1980. Biochemical tests for identification of medical bacteria, $2^{\text {nd }}$ Ed. Williams and Wilkins, Baltimore, USA.

Madi, L. and Y. Henis. 1989. Aggregation in Azospirillum brasilense $\mathrm{Cd}$ : Conditions and factors involved in cell-tocell adhesion. Plant Soil 115:89-98.

Martinez, V.O., M.A. Jorquera, D.E. Crowley, G. Gajardo and M.L. Mora. 2010. Mechanisms and practical considerations involved in plant growth promotion by rhizobacteria. J. Soil Sci. Plant Nutr. 10:293-319.

Michel, B.E. 1983. Evaluation of the water potentials of polyethylene glycol 8000 both in the presence and absence of other solutes. Plant Physiol. 72:66-70.

Mitter, B., A. Petric, M.W. Shin, P.S.G. Chain, L. HaubergLotte, B. Reinhold-Hurek, J. Nowak and A. Sessitsch. 2013. Comparative genome analysis of Burkholderia phytofirmans PsJN reveals a wide spectrum of endophytic lifestyles based on interaction strategies with host plants. Front. Plant Sci. 4:120-132.

Naeem, A.H., Z.A. Zahir, M.A. Akram, H.T. Ahmad and M.B. Hussain. 2015. Isolation and screening of beneficial bacteria to ameliorate drought stress in wheat. Soil Environ. 34:100-110.

Naveed, M., M.B. Hussain, Z.A. Zahir, B. Mitter and A. Sessitsch. 2014. Drought stress amelioration in wheat through inoculation with Burkholderia phytofirmans strain PsJN. Plant Growth Regul. 73:121-131.

Naz, I., A. Bano and Tamoor-ul-Hassan. 2009. Morphological, biochemical and molecular characterization of rhizobia from halophytes of Khewra Salt Range and Attock. Pak. J. Bot. 41:3159-3168.

Nobel, P.S. 1999. Physicochemical and Environmental Plant Physiology, $2^{\text {nd }}$ Ed. Academic Press, San Diego, CA.

Rivera-Cruz, M.C., A. Trujillo-Narcía, G. Córdova-Ballona, J. Kohler, F. Caravaca and A. Roldán. 2008. Poultry manure and banana waste are effective biofertilizer carriers for promoting plant growth and soil sustainability in banana crops. Soil Biol. Biochem. 40:3092-3095.

Rosenblueth, M. and E. Martínez-Romero. 2006. Bacterial Endophytes and Their Interactions with hosts. Mol. Plant-Microbee Interact. 199:827-837.

Sarwar, M., M. Arshad, D.A. Martens and W.T. Frankenberger, Jr. 1992. Tryptophan dependent biosynthesis of auxins in soil. Plant Soil 147:207-215.

Sgroy, V., F. Cassan, O. Masciarelli, M.F. Del Papa, A. Lagares and V. Luna. 2009. Isolation and characterization of endophytic plant growth-promoting (PGPB) or stress homeostasis-regulating (PSHB) 
bacteria associated to the halophyte Prosopis strombulifera. Appl. Microbiol. Biotechnol. 85:371-381.

Smith, L.T. and G.M. Smith. 1989. An osmoregulated dipeptide in stressed Rhizobium meliloti. J. Bacteriol. 171:4714-4717.

Steel, K.J. 1961. The oxidase reaction as a taxonomic tool. J. Gen. Microbiol. 25:297-306.

Steel, R.G.D., J.H. Torrie and D.A. Dicky. 1997. Principles and Procedures of Statistics: A biometrical approach, $3^{\text {rd }}$ Ed. McGraw Hill Book International Co., Singapore.

Trabelsi, D., A. Mengoni, M.E. Aouani, R. Mhamdi and M. Bazzicalupo. 2009. Genetic diversity and salt tolerance of bacterial communities from two Tunisian soils. Ann. Microbiol. 59:1-8.

Vanderlinde, E.M., J.J. Harrison, A. Muszynski, R.W. Carlson, R.J. Turner and C.K. Yost. 2010. Identification of a novel $\mathrm{ABC}$ transporter required for desiccation tolerance and biofilm formation in Rhizobium leguminosarum bv. viciae 3841. Microbiol. Ecol. 71:327340.
Vardharajula, S., S.Z. Ali, M. Grover, G. Reddy and V. Bandi. 2011. Drought-tolerant plant growth promoting Bacillus spp.: Effect on growth, osmolytes, and antioxidant status of maize under drought stress. J. Plant Interact. 6:1-14.

Verma, S.C., J.K. Ladha and A.K. Tripathi. 2001. Evaluation of plant growth promoting and colonization ability of endophytic diazotrophs from deep water rice. J. Biotechnol. 91:127-141.

Vurukonda, S.S.K.P., S. Vardharajula, M. Shrivastava and A. SkZ. 2016. Enhancement of drought stress tolerance in crops by plant growth promoting rhizobacteria. Microbiol. Res. 184:13-24.

Wakelin, S.A., R.A. Warren, P.R. Harvey and M.H. Ryder. 2004. Phosphate solubilization by Penicillium spp. closely associated with wheat roots. Biol. Fertil. Soils 40:36-43.

Yang, J., J.W. Kloepper and C.M. Ryu. 2009. Rhizosphere bacteria help plants tolerate abiotic stress. Trends Plant Sci. 14:1-4. 